\title{
Solution to fading lemonade challenge
}

\author{
Hervé This ${ }^{1,2,3}$ \\ (C) Springer-Verlag GmbH Germany, part of Springer Nature 2019
}

In the fading lemonade challenge [1], it was shown that lemonade is colorless when squeezed lemon is added to the boiled aqueous solution of lemon peel, lemon juice, and mint leaves. Why is there no yellow-green color in this case as it was when no squeezed lemon is used?

This discoloration phenomenon was observed first by a correspondent who proposed that the mechanism was the same as when one adds lemon juice to black tea. It is true that some plant pigments are sensitive to $\mathrm{pH}$, such as the wellknown modification of phenols, for which a very broad interval of colors can be observed. For example, the blue-to-red color imparted by the anthocyanins depends largely on the $\mathrm{pH}$ of the medium [2,3]. However, measurement of the $\mathrm{pH}$ of the lemonade shows no significant difference when squeezed lemons are added and thus the role of phenols in the color change is unlikely to explain this phenomenon.

As no explanation was submitted to the journal, we can analyze rationally the question of color change, discussing first the possible compounds giving the color, and possible compounds "absorbing" (it could be degradation, or release, or adsorption) these compounds.

We know that pigments in plant tissues are generally chlorophylls, carotenoids, phenols, and other substances, such as betalains [4]. Also the derivatives of all these compounds should not be forgotten because they often absorb visible light and because many are formed during the thermal processing

This article is the solution to the Analytical Challenge to be found at https://doi.org/10.1007/s00216-018-1291-4

Hervé This

herve.this@inra.fr

1 INRA, UMR 1145 Ingénierie Procédés Aliments, Group of Molecular Gastronomy, 16 rue Claude Bernard, 75005 Paris, France

2 Ingénierie Procédés Aliments, INRA, AgroParisTech, Université Paris-Saclay, 91300 Massy, France

3 AgroParisTech-Inra International Centre for Molecular Gastronomy, Paris, France of food. For example, the pheophytinization process transforms chlorophylls into pheophytins of darker color $[5,6]$.

In the particular problem that we deal with, one guess could be that chlorophylls and their derivatives, but also carotenoids and phenols, could be responsible for the color of the lemonade when no squeezed lemon is added [7]. Yokoyama and Vandercook separated lemon pigments by chromatography into three fractions with the most polar one being extracted with methanol; these included carotenoids such as lutein, zeaxanthin, violaxanthin, lutoexanthin, auroxanthin, trollein, and neoxanthin that impart yellow to orange colors. However, such compounds have high $\log P$ (e.g., 8.55 for lutein [8], 7.26 for violaxanthin, or 6.89 for neoxanthin) and their effect should be very limited.

As chlorophylls $\left(a, a^{\prime}, b, b^{\prime}\right)$ are also poorly soluble in water, this leaves the possibility that the color (when no squeezed lemon is added) comes from water-soluble derivatives of carotenoids or from chlorophylls, or more probably from anthocyanins, chalcones, aurones, or flavones [9]. However, such an assumption should be considered with caution, as yellow colors appear very frequently when aqueous solutions of organic compounds are thermally processed, because of such chemical processes as hexose dehydration or Fischer, Strecker, or Maillard reactions [10].

Now there is the question of how the potential pigments could be removed from the aqueous solution, and here one could favor the adsorption of colored compounds by the main plant tissue of the squeezed lemon, i.e., cellulose, hemicelluloses, or pectins.

The adsorption of organic compounds on cellulose is much studied, even if the molecular mechanisms are not well understood. Textile dyeing has been practiced empirically for thousands of years, but mechanisms involved in dye adsorption have been studied only since the end of the nineteenth century [11]. Models for dyeing often consider cellulose, as it is one of the main fibers in clothes and the most abundant polymer on the Earth. The chemical composition of the fibers determine, to some extent, the type of dyes that can bind to cellulose [12]. However the ways in which the orientation and crystallinity affect the dye adsorption cannot be predicted today; the difficulties are related to the absence of a molecular model for the dye sorption on fiber and to the exact 
location of the dye bonded to the fiber (in the crystalline or amorphous fiber region). From the molecular point of view, dye adsorption by fiber appears similar to biological ligand-receptor interaction, although it is possible that a textile fiber with both crystalline and amorphous regions will behave as a mixture of receptors of similar, but not identical, nature. On a more practical level, some scientists analyzed how cellulose can extract organic compounds from solution. For example, Namasivayam et al. [13] determined the adsorption of dyes such as Congo Red, Procion Orange, and Rhodamine B on ground orange peels at different concentration and $\mathrm{pH}$ (these pigments have respective $\log P$ of $-0.77,-0.82$, and 0.83 ). The adsorption obeyed both the Langmuir and Freundlich isotherms, and the process of uptake followed first-order rate kinetics; acidic $\mathrm{pH}$ was favorable for adsorption for all three dyes. In a similar study, Johnson and Chandler [14] used HPLC analysis to study the adsorption of naringin $(\log P=-0.16)$ and $\operatorname{limonin}(\log P$ $=2.46$ ) on cellulose monoacetate gel beads; the beads only adsorbed limonin, whereas the process was not effective for removing the other major bitter component, naringin, in citrus fruit juice. Also, Ho et al. [15] observed that the similar dye extraction from aqueous solutions could be performed onto the low-cost sorbent that is sugarcane dust. Of course, cellulose is not the sole possibility for pigment removal from the solution, as pectins too can interact with pigments [16]. Ionic interaction between anthocyanin flavylium cations and free pectic carboxyl groups, and anthocyanin stacking may be two major mechanisms for pectin and anthocyanin binding.

Now we shall finish this brief survey with an interesting observation that citric acid can be important in dyeing. Incorporation of dye stuffs in the finishing bath to establish a single-step process for simultaneous dyeing and creaseresistant finishing has been investigated by Dong et al. [17], because the combined dyeing and finishing process offers a saving in energy and water consumption. Reports in the literature reveal that most of the finishing agents employed in combined dyeing and finishing processes are $N$-methylol-type amides. However, limited information is available on combined dyeing and crease-resistant finishing of cotton fabrics with dyestuffs and polycarboxylic acids, especially citric acid. In Dong et al.'s study, citric acid (a crease-resistant agent) is mixed with reactive dyes, catalyst, and alkali to establish a finishing bath for the one-step dyeing of cotton fabrics. Relatively satisfactory properties of dyed and finished cotton fabric were obtained with appropriate adjustment of the treatment conditions. In their conclusion, Dong et al. write that "The need for a more complete comprehensive study is evident." Isn't it also the case for this challenge? In particular, the main question remains: what is the dye?
Publisher's note Springer Nature remains neutral with regard to jurisdictional claims in published maps and institutional affiliations.

\section{References}

1. This H. Fading lemonade challenge. Anal Bioanal Chem. 2018;410:6339-40. https://doi.org/10.1007/s00216-018-1291-4.

2. This H. Jeux de bicarbonate et enseignement. L'Act Chim. 2012;360-361:78-82.

3. Francies FJ. Anthocyanins. In: Furia E, editor. Current aspects of foods colorants. Cleveland: CRC; 1977. p. 19-28.

4. Milgrom LR. The colours of life: an introduction to the chemistry of porphyrins and related compounds. 1st ed. Oxford: Oxford University Press; 1997.

5. Valverde J, Vignolle M, This H. Quantitative determination of photosynthetic pigments in green beans using thin-layer chromatography and flatbed scanner as densitometer. J Chem Ed. 2007;84: 1505-7.

6. Valverde J, This H. ${ }^{1} \mathrm{H}$ NMR quantitative determination of photosynthetic pigments from green beans (Phaseolus vulgaris L.). J Agric Food Chem. 2008;56(2):314-20. https://doi.org/10.1021/ jf070277j.

7. Yokoyama H, Vandercook CR. Citrus carotenois. I. Comparison of carotenoids of mature-green and yellow lemons. J Food Sci. 1967;32:42-8.

8. Sy C, Gleize B, Dangles O, Landrier JF, Caris Veyrat C, Borel P. Effects of physicochemical properties of carotenoids on their bioaccessibility, intestinal cell uptake, and blood and tissue concentrations. Mol Nutr Food Res. 2012;56:1385-97.

9. Geissman TA. Anthocyanins, chalcones, aurones, flavones and related water-soluble plant pigments. In: Paech K, Tracey MV, editors. Moderne Methoden der Pflanzenanalyse/Modern Methods of Plant Analysis. Berlin: Springer-Verlag; 1955.

10. This H. "Maillard products" and "Maillard reactions" are much discussed in food science and technology, but do such products and reactions deserve their name? Acad Note Fr Acad Agric. 2016;3:1-10.

11. Timofei S, Schmidt W, Kurunczi L. Simon Z. A review of QSAR for dye affinity for cellulose fibres. Dyes Pigments. 2000;47:5-16.

12. Peters RH. Textile chemistry. The physical chemistry of dyeing. Vol III. Amsterdam: Elsevier; 1975.

13. Namasivayam C, Muniasamy N, Gayatri K, Rani M, Ranganathan $\mathrm{K}$. Removal of dyes from aqueous solutions by cellulosic waste orange peel. Bioresource Technol. 1996;57:37-43.

14. Johnson RL, Chandler BV. Reduction of bitterness and acidity in grapefruit juice by adsorptive process. J Sci Food Agric. 1962;33: 287.

15. Ho HS, Chiu WT, Wang CC. Regression analysis for the sorption isotherms of basic dyes on sugarcane dust. Bioresource Technol. 2005;96(11):1285-91.

16. Lin Z, Fisher J, Wicker L. Intermolecular binding of blueberry pectin-rich fractions and anthocyanin. Food Chem. 2016;194: 986-93.

17. Dong Y, Wang J, Liu P. Dyeing and finishing of cotton fabric in a single bath with reactive dyes and citric acid. Color Technol. 2001;117:262-5. 